\title{
AVALIAÇÃO DAS NORMAS REGULATÓRIAS SOBRE ROTULAGEM E EMBALAGEM DE PRODUTOS FARMACÊUTICOS
}

\section{ARTIGO DE REVISÃO}

NOVAES, Michele Franciene Baú ${ }^{1}$

NOVAES, Michele Franciene Baú. Avaliação das Normas Regulatórias sobre rotulagem e embalagem de produtos farmacêuticos. Revista Científica Multidisciplinar Núcleo do Conhecimento. Ano 05, Ed. 06, Vol. 01, pp. 44-64. Junho de 2020.

ISSN:

2448-0959,

Link

de

acesso: https://www.nucleodoconhecimento.com.br/saude/normas-regulatorias

\section{RESUMO}

A Agência Nacional de Vigilância Sanitária (ANVISA) tem por finalidade promover a saúde da população por meio da regulamentação da produção e da comercialização de produtos e serviços submetidos à vigilância sanitária, dentre eles os produtos farmacêuticos. As normas regulatórias norteiam os parâmetros de qualidade que devem ser seguidos na cadeia produtiva na indústria farmacêutica de medicamentos. A presente pesquisa procurou levantar dados bibliográficos para esclarecer e tornar público informações aos profissionais de saúde, ao setor industrial farmacêutico, as autoridades representativas vinculadas ao Ministério da Saúde, ANVISA e a população brasileira, em geral, sobre a importância de discutir e atualizar as legislações brasileiras sobre a rotulagem e embalagem de produtos farmacêuticos, identificar e demonstrar dados que apontam possíveis equivalências entre os mesmos que possam conduzir a erros de medicação, passíveis de acontecer por troca. Pretende-se também verificar junto às normas sanitárias atuais quais são as informações obrigatórias a serem inseridas nos rótulos, relevantes a segurança do usuário, e discutir sobre possíveis reações adversas relacionadas ao excipiente

\footnotetext{
1 Pós-graduanda em Gestão Industrial Farmacêutica pela Universidade Estácio de Sá, Graduada em Farmácia-Bioquímica pela Universidade Paulista - UNIP.
} 
lactose, amplamente utilizado pela indústria farmacêutica. Para selecionar o referencial teórico foram utilizados os banco de dados dos sites Scielo.br, BVS (Biblioteca Virtual em Saúde), pesquisas em sites, revistas científicas e artigos em revistas de saúde, onde utilizou-se as palavras de busca isoladas: rotulagem, embalagem, legislação, lactose, e busca combinada de duas ou três palavras: rótulos de medicamentos-erros de medicação, farmacovigilância-erros de medicação, rotulagem-embalagem-legislação, rótulos-embalagens-lactose. Os trabalhos que não combinavam nenhuma das três palavras foram excluídos, assim como os que não se enquadravam nos anos pré-selecionados de 2000 a 2019. O critério de exclusão também se aplica para os artigos que após leitura que não se referiam ao objetivo principal da pesquisa. Observou-se a falta de normas específicas para garantir a diferenciação de embalagens semelhantes para evitar erros de medicação, como também foi notada a falta de regras para discriminar a presença de lactose em rótulos de medicamentos. A publicação de legislação para promover a diferenciação de embalagens e a padronização de informações específicas em rótulos é fundamental para a promoção do uso racional de medicamentos.

Palavras-chave: Rotulagem de medicamentos, embalagem, erros de medicação. Legislação, lactose.

\section{INTRODUÇÃO}

A Agência Nacional de Vigilância Sanitária (ANVISA) tem por finalidade promover a saúde da população monitorando a produção e da comercialização de produtos e serviços submetidos à vigilância sanitária, incluindo os produtos farmacêuticos, por meio da fiscalização, normatização de procedimentos e processos a serem seguidos a fim de garantir a qualidade e a segurança no uso destes produtos (BRASIL, 1999).

A cadeia de produção industrial de produtos farmacêuticos engloba uma série de procedimentos sequenciais que visam garantir a qualidade, desde os estudos préformulação até o desenvolvimento da rotulagem e do material de embalagem adequado. 
A qualidade de um produto farmacêutico deve ser observada desde os processos de produção dos ativos até no rótulo e embalagem, os quais devem atender todas as exigências legais.

A Resolução ANVISA RDC ํo 71/2009 estabelece as especificações, o aspecto e o conteúdo que os rótulos e embalagens de medicamentos devem ser desenvolvidos no Brasil, de forma a facilitar o acesso às informações necessárias sobre estes produtos e garantir o uso racional dos medicamentos (BRASIL, 2009).

A finalidade da embalagem é acondicionar, envasar, empacotar, proteger e manter seguro, e propiciar a conservação adequada do produto farmacêutico, constituindo um elemento importante na eficácia e segurança, além de veicular as informações essenciais quanto à administração. Nos rótulos deve constar o nome comercial do produto, se houver nome do princípio ativo, a forma farmacêutica, via de administração, dosagem e quantidade acondicionada no material de embalagem (BRASIL, 2009).

A Constituição Federal em um de seus artigos dispõe que a saúde é garantida a todos e é dever do Estado proporcioná-la, por meio de políticas socioeconômicas que tendam à reduzir o probabilidade dos cidadãos desenvolverem doenças ou outros agravos, e o acesso às ações e serviços para a promoção e proteção da saúde de todos os cidadãos brasileiros (BRASIL, 1988).

O Código de Defesa do Consumidor dispõe que é direito do consumidor a garantia da proteção da vida e as informações adequadas e claras sobre os produtos e serviços. Os produtos desenvolvidos não podem vir a acarretar riscos à saúde ou a segurança dos consumidores, e, no caso específico de produtos produzidos em meio industrial, o fabricante deve prestar todas as informações necessárias e estas devem vir acompanhadas do produto, especialmente informações relativas à segurança do uso (BRASIL, 1990).

A Organização Mundial da Saúde publicou em 1998 o documento "The Role of the Pharmacist in Self-Care and Self-Medication", relatório do $4^{\circ}$ Grupo Consultivo da 
OMS sobre o papel do farmacêutico, documento este que também relata a importância sobre o acesso à informação imparcial e de qualidade para orientar o autocuidado e a automedicação (WHO, 1998).

Os erros de dispensação e administração de medicamentos são derivados de consequências multifatoriais, tendo origens e causas diversas, desde os erros provocados pela dispensação e/ou administração incorreta até aqueles derivados da automedicação inconsciente de produtos que contenham substâncias que podem gerar problemas ou agravos à saúde de pacientes (WHO, 1998).

Dados científicos apontam que rótulos e embalagens semelhantes de produtos farmacêuticos podem ser um dos motivos responsáveis por ocasionar erros de dispensação e administração de medicamentos em hospitais e estabelecimentos de saúde (ANACLETO et al., 2005).

Outras pesquisas mostram que, o uso de alguns excipientes em preparações farmacêuticas, amplamente utilizados pelas indústrias na fabricação de medicamentos, como a lactose, pode ocasionar o desenvolvimento de desconfortos gastrointestinais em pessoas com intolerância a este tipo de carboidrato, tanto na população infantil quanto em adultos quando da administração de medicamentos que contenham este excipiente na preparação (SENA, 2012; SILVA, 2008).

Situações como estas citadas podem levar à hospitalização ou aumentar o tempo de permanência do paciente internado, trazendo consequências a saúde das pessoas e a elevação dos custos dispendidos para os sistemas de saúde tanto público como privado.

Podemos considerar ocorrências como as mencionadas anteriormente como um problema de saúde pública a ser analisado, e devemos discutir as legislações envolvidas no processo de rotulagem e embalagem de produtos farmacêuticos, de modo a garantir o direito à saúde plena e a informação acessível e clara ao usuário.

Partindo-se destas ocorrências, esta pesquisa pretende avaliar as normas regulatórias atuais em vigor no Brasil sobre a rotulagem e embalagem de produtos farmacêuticos, 
analisar dados epidemiológicos sobre erros de medicação derivados de embalagens semelhantes, relatar a ocorrência de reações adversas derivadas do uso de

medicamentos contendo o excipiente lactose, com a finalidade de verificar a necessidade de discussão e atualização da legislação brasileira sobre o tema, para facilitar e garantir o acesso da população de informações essenciais quanto aos medicamentos.

\section{ATRIBUIÇÕES DA ANVISA E AS NORMAS REGULATÓRIAS BRASILEIRAS SOBRE ROTULAGEM E EMBALAGEM DE MEDICAMENTOS}

A Agência Nacional de Vigilância Sanitária, órgão vinculado ao Ministério da Saúde e caracterizada pela independência administrativa, tem como uma de suas atribuições gerais a responsabilidade pela normatização, controle e fiscalização de produtos, substâncias e serviços relacionados à saúde, agir na promoção da saúde e desenvolver trabalhos em situações especiais que coloquem em risco a saúde da população brasileira (BRASIL, 1999).

Como atribuições específicas dessa entidade, podemos citar o estabelecimento de normas para regular o setor de medicamentos, como padronização de parâmetros de qualidade para fabricação; autorizar e cancelar registros de insumos e produtos farmacêuticos; desenvolver debates e consultas públicas sobre assuntos pertinentes a saúde para alterar ou criar novas regras como fonte de embasamento as atividades desenvolvidas nas áreas de produção e comercialização de medicamentos; e analisar as solicitações das indústrias farmacêuticas para alterações de rótulos e embalagens (BRASIL, 1999).

O desenvolvimento da civilização num mundo globalizado, o aparecimento de novas patologias a serem investigadas pela medicina, e com as melhorias conquistadas nas últimas décadas com relação à facilidade do acesso aos medicamentos pela população brasileira, em comparação com décadas anteriores, observou-se um 
aumento no uso de medicamentos e procura por melhores terapias para atendimento as novas doenças da modernidade.

Em consequência da demanda por novas alternativas terapêuticas mais eficazes e modernas, percebeu-se a necessidade de desenvolver novos insumos farmacêuticos, delineamento de fórmulas farmacêuticas e sistemas de liberação de fármacos. Com isso, houve um aumento nos investimentos por parte das indústrias em pesquisas e desenvolvimento de novas moléculas, e em decorrência disso e dos interesses econômicos do setor, têm-se um aumento considerável na disponibilidade de fármacos.

Os rótulos e embalagens de medicamentos passaram a ser não somente parte integrante para acondicionamento do produto acabado, mas para o marketing farmacêutico uma oportunidade importante para o estudo e desenvolvimento de embalagens atrativas do ponto de vista comercial, que ajudassem a promover o produto e aumentar as vendas. Surge então, a necessidade de estabelecer normas sanitárias para a rotulagem desses produtos.

Considerando os critérios para Boas Práticas de Fabricação, que se aplicam a todas as etapas de pesquisa, produção e logística de um produto, e a Política Nacional de Medicamentos instituída pelo Ministério da Saúde em 1998, que tem como um de seus princípios o incentivo à produção de medicamentos e a sua regulamentação sanitária, a Agência Nacional de Vigilância Sanitária publicou a Resolução RDC no 333/2003 (BRASIL, 2003; BRASIL, 2019).

A Resolução da Diretoria Colegiada da ANVISA RDC no 333/2003 foi a primeira legislação desenvolvida a respeito da rotulagem de medicamentos, instituindo que todas as embalagens de medicamentos desenvolvidas a partir do ano seguinte à publicação deveriam se adequar as normas estabelecidas por aquela resolução (BRASIL, 2003). Posteriormente, essa norma foi revogada pela publicação da Resolução RDC nำ 71/2009. 
A Resolução RDC no 71/2009 é a norma vigente atualmente no Brasil que regulamenta quais as características que devem ser observadas para o desenvolvimento da rotulagem de medicamentos no Brasil, de modo a facilitar o acesso às informações e padronizar as informações obrigatórias a serem inseridas (BRASIL, 2009).

As empresas deveriam notificar a adequação da rotulagem, cumprindo as exigências estabelecidas na resolução, e disponibilizar novos rótulos nas embalagens dos medicamentos produzidos ou importados para venda no mercado em até 540 dias a partir da data da publicação (BRASIL, 2009).

Algumas definições são apresentadas nesta norma para tipos de rotulagem e sua destinação de uso, podendo ter rotulagem diferenciada e com características que permitem ser identificado como rótulo desenvolvimento para uso em produtos dispensados em instituições públicas ligadas ao Ministério da Saúde; comercial, com rotulagem desenvolvida para produtos com vendas em farmácias e drogarias; e hospitalar, com material destinado a acondicionar produtos de uso restrito para clínicas e hospitais. São caracterizados ainda, os conceitos para rótulo e diferenciação de tipos de embalagem (BRASIL, 2009).

Rótulo é toda espécie de identificação impressa ou gravada no material de rotulagem que tenha como finalidade a identificação de informação importantes em recipientes, vasilhames, invólucros, envoltórios ou sobre o produto no qual se deseja identificar (BRASIL, 2009).

Embalagem é toda espécie de forma para acondicionamento, com a finalidade principal de agregar unidades de um produto, objetivando criar melhores condições para manter a qualidade e a distribuição logística do mesmo (BRASIL, 2009).

Em se tratando de medicamentos, ainda temos os conceitos de embalagem primária e secundária. De acordo com a RDC no 71/2009, embalagem primária é aquela que mantém contato direto com o produto farmacêutico, enquanto que a embalagem secundária é a embalagem externa do produto, que fica em contato com a embalagem primária podendo conter uma ou mais embalagens primárias (BRASIL, 2009). 
Segundo a legislação acima citada, há informações cuja inserção se torna obrigatória no processo de rotulagem para esclarecimento sobre as características do medicamento.

Nos rótulos de embalagens secundárias, devem conter: o nome comercial do medicamento e sua denominação genérica de cada princípio ativo constante na formulação, com a concentração de cada um deles; a via de administração, a forma farmacêutica, com indicação de restrição de uso por faixa etária, indicando se o produto é destinado ao uso adulto ou pediátrico; a quantidade total acondicionada no material de embalagem, com a indicação da temperatura e condições de armazenamento; e informações a respeito do fabricante e dados de registro do produto (BRASIL, 2009).

Ainda devem ser inseridas frases de advertência ao usuário com relação a contraindicações, precaução e advertência para o uso de princípios ativos, classe terapêutica e excipientes, quando for o caso, nas embalagens secundárias. Porém, a RDC no 71/2009 não aponta especificamente quais frases de advertências com relação a princípios ativos e excipientes devem constar nos rótulos e embalagens (BRASIL, 2009).

Com relação aos rótulos de embalagens primárias, verificou-se que as mesmas informações obrigatórias para a embalagem secundárias devem ser inseridas na embalagem primárias e quando não for possível constar todas essas informações no material de embalagem primário, as indústrias devem informar os motivos via peticionamento eletrônico (BRASIL, 2009).

A rotulagem de medicamentos é o veículo de comunicação de informações do produto ao usuário. Nesse sentido, a agência reguladora brasileira tem importante papel para analisar e estabelecer critérios através da publicação de novos atos normativos para o desenvolvimento de rótulos e embalagens adequadas às necessidades da população e mais eficientes do ponto de vista informativo. 


\section{RÓTULOS E EMBALAGENS DE MEDICAMENTOS SEMELHANTES E OS ERROS DE MEDICAÇÃO}

As questões relacionadas à segurança do paciente envolvem ações para prevenção e eliminação de erros envolvidos nos processos de saúde. De acordo com o United States National Coordinating Council for Medication Error Reporting and Prevention (NCCMERP), erro de medicação pode ser definido como:

qualquer evento evitável que possa causar ou levar ao uso inadequado de medicamentos ou danos ao paciente enquanto o medicamento está sob o controle do profissional de saúde, do paciente ou do consumidor. Tais eventos podem estar relacionados à prática profissional, aos produtos para o cuidado de saúde, aos procedimentos e aos sistemas, incluindo prescrição, comunicação, rótulo dos produtos, embalagem, nomenclatura, composição, dispensação, distribuição, administração, educação, monitoramento e uso (NCCMERP, 2015).

Segundo a Organização Mundial da Saúde, erros de medicação são um dos principais motivos de lesões e danos evitáveis nos sistemas de saúde, podendo acontecer em diferentes etapas do processo de uso de medicamentos. Mundialmente, o custo advindo de erros relacionados a medicamentos é estimado em 42 bilhões de dólares por ano (WHO, 2017).

A publicação da Lei oㅜ 13.236/2015 culminou na alteração e inclusão de alguns artigos da Lei no 6360/1976, para reforçar a necessidade de distinguir rótulos e embalagens de medicamentos de modo a minimizar a ocorrência de erros de medicação, incluindo os erros decorrentes de dispensação, administração de medicamentos ou troca equivocada por apresentarem embalagens semelhantes (BRASIL, 2015).

Os rótulos e embalagens de medicamentos, além de comunicar as características para reconhecimento e uso destes, tem a finalidade de constituir importante meio para evitar erros. No entanto, dados apontam para erros de medicação em que rótulos e embalagens de medicamentos podem ser a causa de confusão por parte dos 
profissionais de saúde nos procedimentos realizados no ambiente de trabalho, e por consequência prejudicam a saúde de pacientes (ANACLETO et al., 2005).

Os erros de medicação constituem um grande problema de saúde pública e são responsáveis pela ocorrência de morbidade, hospitalizações, mortalidade e aumento dos gastos em saúde. Segundo publicação no ano de 2018 do Instituto para Práticas Seguras para o Uso de Medicamentos, dentre os erros relacionados a medicamentos, $33 \%$ são causados por rótulos e embalagens, sendo que $31 \%$ desses evoluíram para fatalidades relacionadas (ISMP, 2018).

Estudo epidemiológico do tipo observacional e transversal foi realizado em 2010 em diferentes setores da farmácia hospitalar de um hospital universitário em Fortaleza, Ceará, com a finalidade de verificar rótulos e embalagens de medicamentos, identificando semelhanças nos mesmos que poderiam desencadear erros de medicação possíveis de ocorrer nos processos de armazenamento, dispensação e administração (LOPES et al., 2012).

Foram examinadas 300 apresentações farmacêuticas fotografadas (150 duplas) e apresentadas para observadores em dias distintos, sendo os observadores participantes do estudo dois enfermeiros e um farmacêutico (LOPES et al., 2012).

As apresentações farmacêuticas da amostra do estudo incluíram medicamentos de referência, genéricos, similares e medicamentos com embalagem do Ministério da Saúde. Foram analisadas formas e apresentações farmacêuticas, tipos de embalagens, nome, cor, desenho, classe farmacológica, fornecedores e o potencial de risco; considerando medicamentos potencialmente perigosos e medicamentos controlados (LOPES et al., 2012).

Para a seleção das amostras foram considerados os medicamentos de referência, genéricos, similares e os medicamentos com embalagens do Ministério da Saúde. Na ocorrência de semelhanças, os dados foram inseridos em banco de dados e caracterizados a partir de referências internacionais como o National Coordinating Council for Medication Error Reporting and Prevention (NCCMERP, 2017). 
Após a apresentação das fotos aos observadores, coleta das respostas obtidas por estes e análise dos dados através de métodos estatísticos, os pesquisadores encontraram os seguintes resultados: quanto ao tipo de medicamento, $43 \%$ das embalagens semelhantes eram de medicamentos similares, $21,33 \%$ de medicamentos de referência e 18\% medicamentos genéricos; e, dentre as 24 classes farmacológicas pesquisas, 28\% eram antimicrobianos, 10,67\% anestésicos e 6,67\% anti-hipertensivos (LOPES et al., 2012).

Foram encontrados também, semelhanças quanto aos dados impressos, ao designer, cor dos rótulos, embalagem com mesma cor. Os pesquisadores identificaram que; entre a amostra analisada, $50 \%$ das embalagens primárias e $44 \%$ das embalagens secundárias apresentavam a mesma cor (LOPES et al., 2012).

A investigação das apresentações farmacêuticas estudadas nesta pesquisa mostrou também que, no total dos medicamentos possivelmente semelhantes, $51,33 \%$ eram soluções parenterais de pequeno volume incluindo ampolas, frascos-ampola e bolsas de sistema fechado, demonstrando a influência que o tema da rotulagem e embalagem de medicamentos tem na capacidade de possibilitar erros de medicação (LOPES et al., 2012).

Como representação da observação problema apresentada nesta pesquisa, procurouse identificar para exemplificação alguns rótulos e embalagens semelhantes de medicamentos. Algumas imagens foram encontradas a partir de pesquisa em sites.

O Ministério da Saúde em 2016 atualizou o Manual de Identidade Visual de Embalagens de Medicamentos, que estabeleceu os critérios para desenvolvimento e identificação da rotulagem de medicamentos distribuídos pelo Sistema Único de Saúde.

A figura 1 apresenta medicamentos injetáveis produzidos e distribuídos pelo Ministério da Saúde para uso no SUS (Sistema Único de Saúde) e representa a semelhança na rotulagem de dois tipos de insulinas diferentes, cuja possível troca pode colocar em risco o paciente caso venha ocorrer administração errônea de insulina humana regular 
(embalagem apresentada no lado esquerdo da imagem) ao invés de insulina humana NPH (apresentada no lado direito da imagem).

A figura 2 apresenta embalagens semelhantes de medicamentos com substâncias controladas que são classificadas como anticonvulsivantes, comumente utilizadas para prevenir o desencadeamento de crises convulsivas em pacientes portadores de epilepsia. O nome do fabricante gravado na parte inferior da embalagem foi propositalmente coberto com marcado em preto para não expor a marca e evitar possíveis questionamentos quanto aos interesses da presente pesquisa.

Figura 1. Embalagem semelhante de insulina e o potencial para erro de medicação.

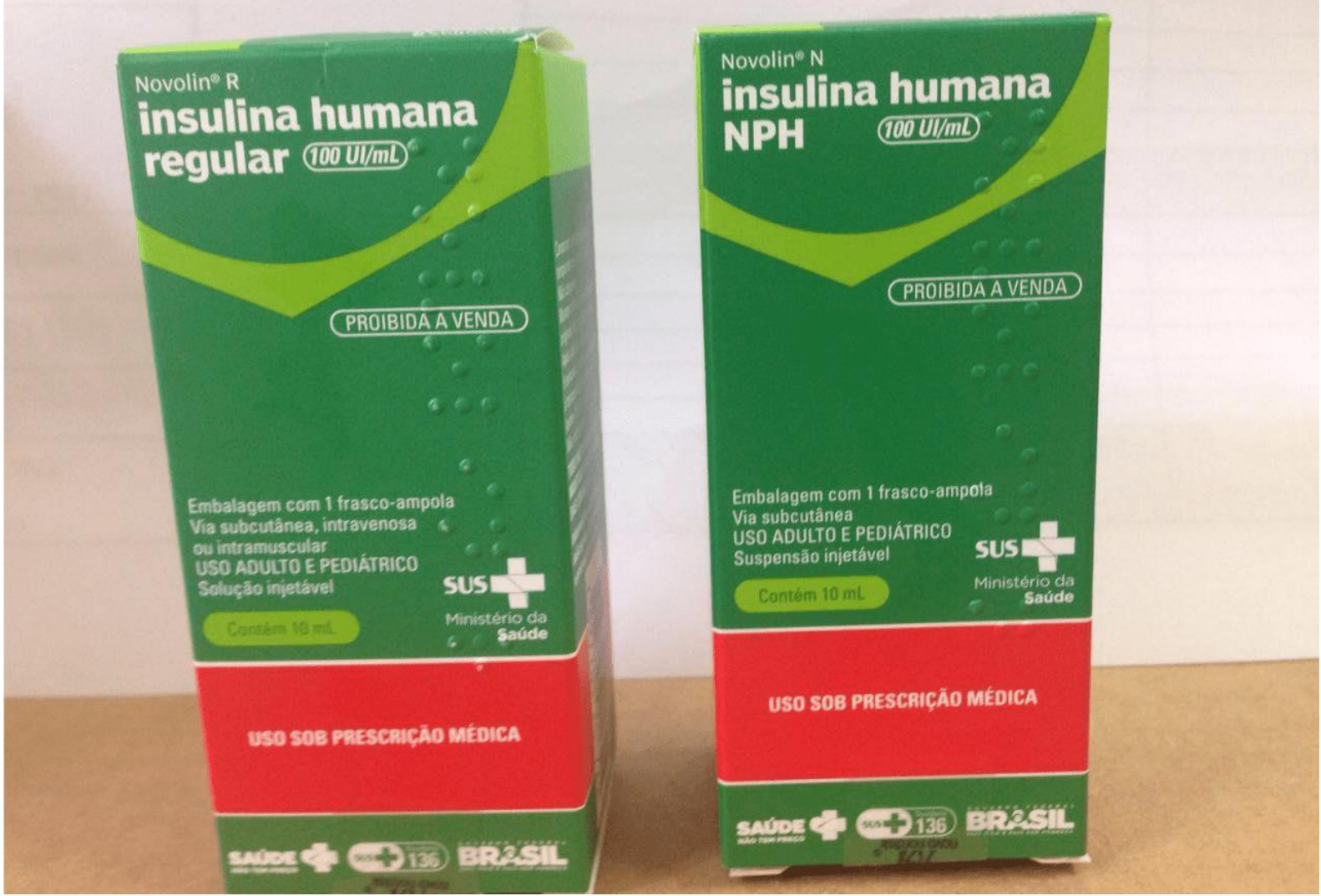


Figura 2. Embalagens semelhantes de anticonvulsivantes fabricados no Brasil.

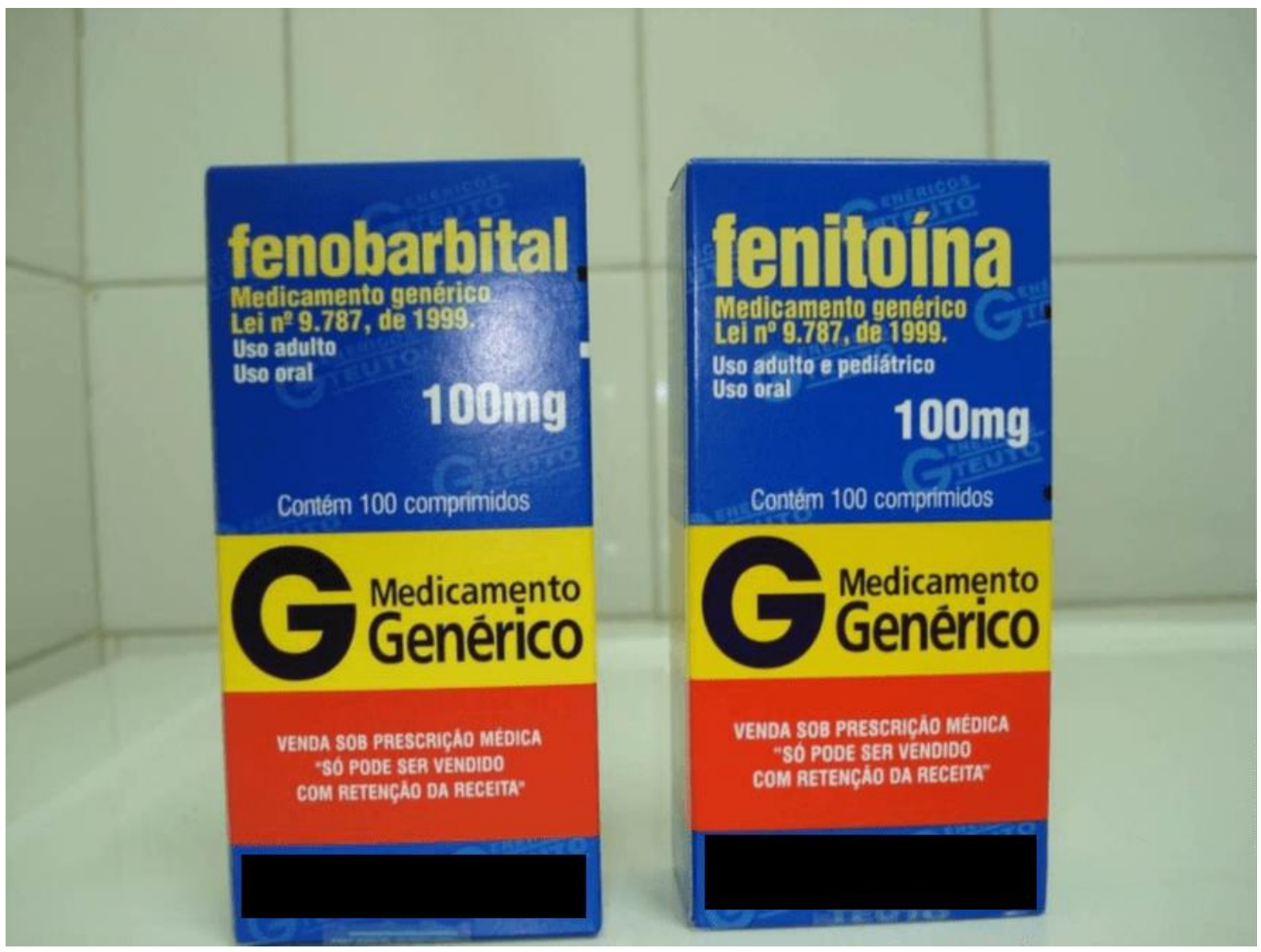

Fonte: ISMP, 2019 - Instituto para Práticas Seguras no Uso de Medicamentos.

Outra semelhança na rotulagem de medicamentos foi identificada pelo próprio autor desta pesquisa enquanto era responsável pela prestação de assistência farmacêutica em um hospital na cidade de Votorantim, interior do Estado de São Paulo, Brasil, a partir da observação do estoque da farmácia do centro cirúrgico, nas caixas (denominadas "psicobox") destinadas ao uso pelos médicos anestesistas nas salas de cirurgia, onde foi relatado pela equipe a ocorrência de erro de administração entre lidocaína e bupivacaína.

As ampolas dos medicamentos injetáveis de lidocaína e bupivacaína encontradas nas caixas foram analisadas e apresentavam potencial de semelhança para induzir erro de medicação, tanto para a dispensação quanto à administração em pacientes em procedimentos cirúrgicos. 
Vale ressaltar que as ampolas dessas duas substâncias têm a mesma empresa como fabricante e para efeito de observação da semelhança foram colocadas, empiricamente, várias destas ampolas lado a lado com a introdução de uma ampola de substância diferente entre as demais para análise do potencial de semelhança. As Figuras 3 e 4 abaixo apresentam a situação descrita.

Figura 3. Medicamentos injetáveis utilizados em procedimentos cirúrgicos e aspectos da rotulagem.

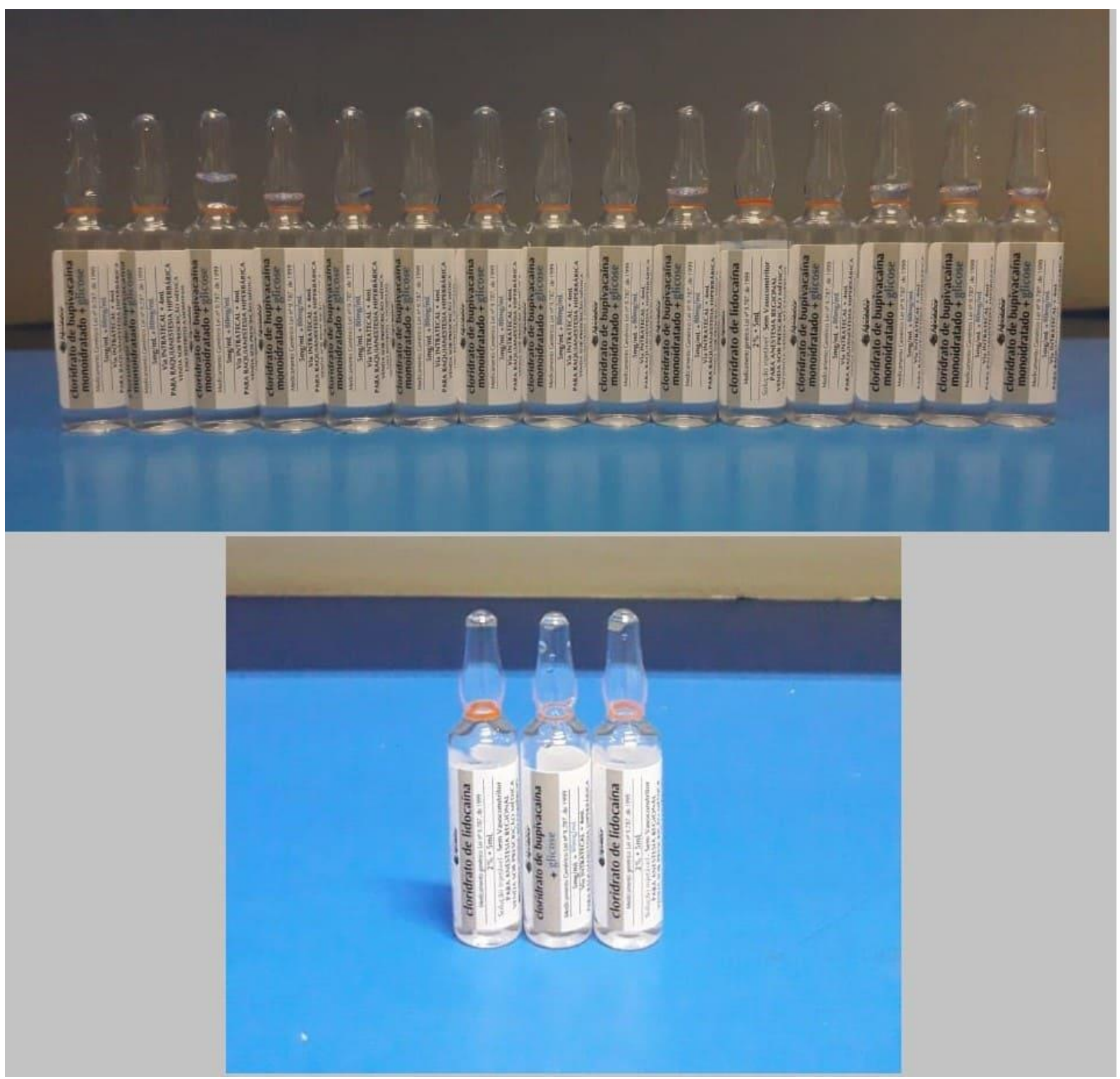

Fonte: do Autor. 
Figura 4. Foto ampliada. Medicamentos injetáveis utilizados em procedimentos cirúrgicos e aspectos da rotulagem.

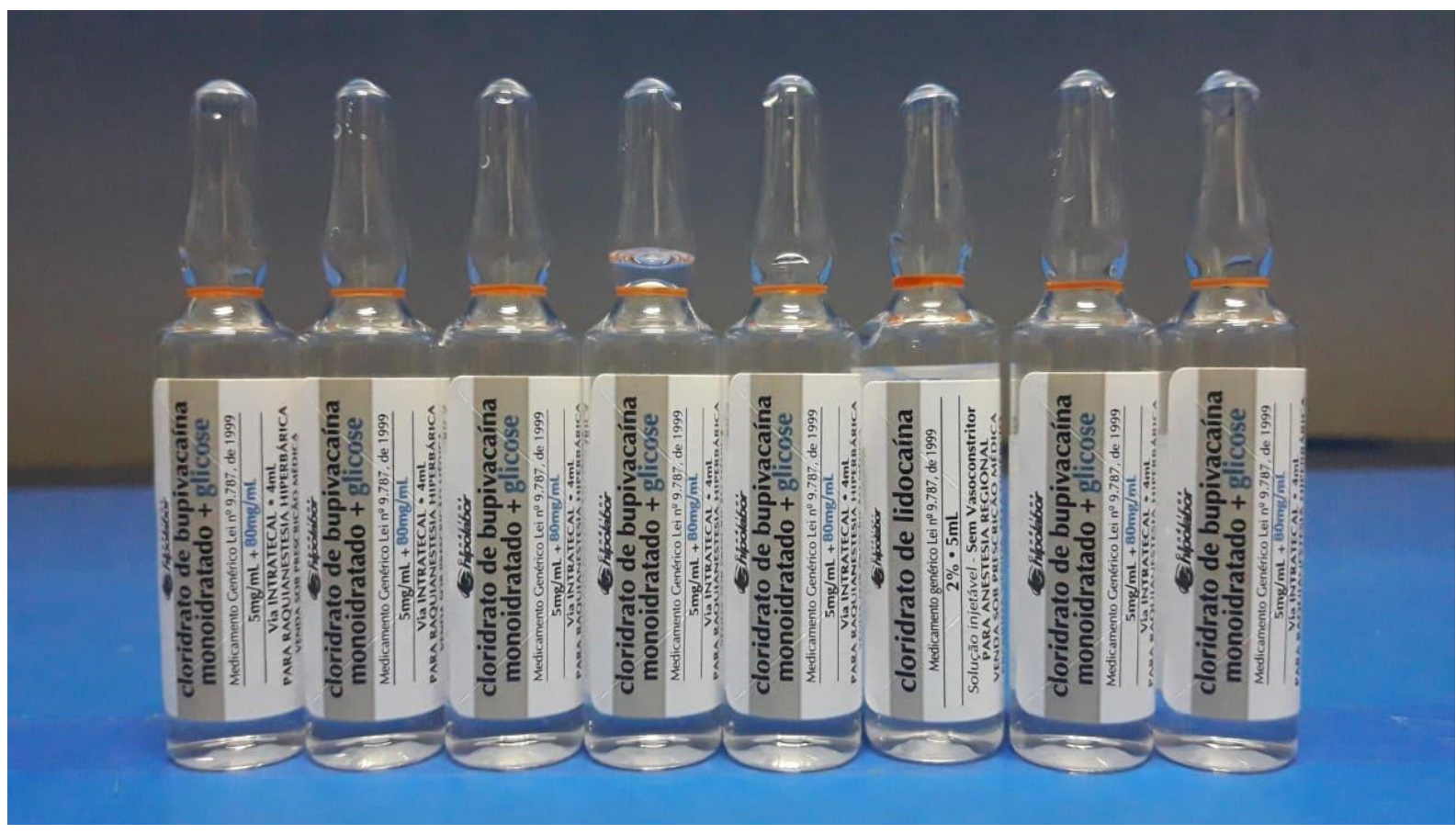

Fonte: do Autor.

Outra pesquisa publicada na revista do Instituto Israelita de Ensino e Pesquisa Albert Einstein, procurou demonstrar que as cores ajudam no processo de identificação visual de colírios, reduzindo a administração incorreta dos mesmos. Foram retirados os rótulos das embalagens dos produtos testados e incentivada a identificação dos colírios pelos pacientes a partir da cor característica de cada apresentação. Os pesquisadores concluíram que a coloração da substância do medicamento pode auxiliar no processo de visualização e identificação de medicamentos (COSTA et al., 2019).

A partir dessa pesquisa e dos dados apresentados anteriormente, empiricamente, podemos entender que as cores interferem na identificação de medicamentos, tanto na substância ativa presente, como também poderiam influenciar positivamente no processo de rotulagem e embalagem de produtos farmacêuticos. 
Cores diferentes sendo utilizadas nos processos de desenvolvimento de material de embalagem para melhorar a distinção da rotulagem, como ampolas, frascos-ampola, bolsas de soluções parenterais, vidrarias, blísteres, dentre outras, diminuíram a possibilidade erros por troca.

\section{O USO DE LACTOSE COMO EXCIPIENTE FARMACÊUTICO}

Nos estudos para o delineamento de novas fórmulas farmacêuticas são analisadas as características biofarmacêuticas e físico-químicas dos princípios ativos e excipientes. Formas farmacêuticas necessitam de adjuvantes para auxiliar nos processos como a solubilidade, compressão, conservar, dar volume, forma ao medicamento e conferir sabor agradável a formulação para melhorar a aceitação do consumidor (AULTON, 2016).

A lactose é um carboidrato dissacarídeo, sendo um dos tipos de excipiente comumente utilizados pela indústria, e que se apresenta como diluente e edulcorante, principalmente em formas farmacêuticas sólidas, podendo ainda interferir nas características farmacocinéticas. Uma contraindicação do uso deste excipiente em preparações farmacêuticas seria o fato de algumas pessoas apresentarem intolerância a lactose (AULTON, 2016; 1475).

A intolerância à lactose é uma condição do organismo onde existe a incapacidade da digestão deste carboidrato por deficiência da enzima digestiva lactase, que transforma a lactose em glicose e galactose, sendo uma condição que causa problema a vida de pessoas em todo o mundo (PEREIRA; FERREIRA; MARQUES, 2019).

As pessoas que são apresentam essa condição, sofrem com desconfortos gastrointestinais, como o desenvolvimento de diarreia severa prolongada, flatulência, cólicas, inchaço abdominal e desidratação, o que as leva a não consumir leite e demais produtos laticínios (PERREIRA; FERREIRA; MASQUES, 2019).

Pacientes portadores de intolerância à lactose estão sujeitos a reações adversas decorrentes do uso de medicamentos contendo esse excipiente, podendo desenvolver 
sintomas semelhantes aqueles ocorridos quando do consumo de alimentos que contém este açúcar, visto que a ingestão da quantidade igual ou inferior a 3 gramas já pode provocar os sintomas descritos (SENA et al., 2014).

Estudo descrito realizado no Centro de Farmacovigilância do Ceará objetivou identificar a existência de possíveis excipientes indutores de reações adversas contidos em 12 produtos (35 apresentações farmacêuticas) com maior venda no Brasil, sendo a coleta da amostra feita no período de agosto a setembro de 2004 (SILVA et al., 2008).

A lactose estava presente entre os adjuvantes farmacêuticos encontrados nos produtos estudados, como na formulação contendo bromazepam (substância de uso controlado cuja aquisição necessita de receituário específico) e dipirona associada à butilescopolamina (SILVA et al., 2008).

Outro estudo descritivo com levantamento bibliográfico da composição dos medicamentos, através da bula e das informações técnicas registradas na ANVISA, avaliou o risco de possíveis excipientes que causam reações adversas em medicamentos anticoncepcionais. A amostra foi caracterizada por 6 apresentações de anticoncepcionais, sendo que 3 eram medicamentos referência e outros 3 eram similares, e em todos foi encontrada a presença de lactose na composição (DE CASTRO et al., 2010).

Pesquisa realizada com medicamentos frequentemente prescritos a pacientes pediátricos, também analisou a presença lactose em 181 diferentes apresentações de 42 medicamentos. Os grupos farmacológicos encontrados foram: analgésicos/antipiréticos, anti-inflamatórios não esteroides, antibióticos, antihistamínicos, antieméticos, corticoides orais, corticoides inalatórios, broncodilatadores de ação prolongada, corticosteroides inalatórios associados a broncodilatadores, antileucotrienos e estabilizadores da membrana de mastócitos. Com relação a presença de lactose, $28 \%$ das apresentações continham este excipiente (GERMANA, et al. 2009). 
As pesquisas verificadas mostram dados que identificam a presença da lactose em percentual considerável dentre os produtos analisados. Atualmente no Brasil não existe legislação que regulamente os fabricantes de medicamentos acrescentar na parte externa da embalagem a informação que o medicamento apresenta o excipiente lactose.

Embalagens secundárias de medicamentos estão em contato direto com o produto e são comumente identificadas pela população leiga em legislação farmacêutica como a parte externa e primeira visualmente identificada: "a caixinha do remédio". Considerando que outras informações de alerta a respeito de corantes já foram inseridas na rotulagem de medicamentos por meio de legislação, como por exemplo a tartazina, seria interessante considerar inserir o alerta também sobre a lactose na parte externa, facilitando a identificação.

A rotulagem poderia auxiliar de forma relevante pessoas portadoras de intolerância à lactose para tomar melhores decisões quanto a escolha e compra de seus medicamentos. Projeto de lei apresentado à Câmara dos Deputados em 2009, previa obrigar os laboratórios farmacêuticos inserirem nos rótulos dos medicamentos alerta sobre a existência da lactose na composição de seus produtos. Apesar o tema do projeto de lei ser relevante para o uso seguro e racional de medicamentos, a proposta foi analisada e arquivada em 2013.

\section{O DIREITO AO ACESSO ÀS INFORMAÇÕES DE SAÚdE E A ROTULAGEM DE MEDICAMENTOS}

A saúde é direito de todos e dever do Estado, garantido mediante políticas sociais e econômicas que visem à redução do risco de doença e de outros agravos, e ao acesso universal e igualitário às ações e serviços para sua promoção, proteção e recuperação (BRASIL, 1988).

O direito à saúde está inserido no âmbito dos direitos sociais constitucionalmente garantidos (BRASIL, 1988). Baseando-se na Constituição Federal como princípio para evidenciar o direito à saúde e informações derivadas desse direito, cabe à agência 
regulatória brasileira como parte integrante e representativa do Ministério da Saúde, a responsabilidade por tomar iniciativas que venham a desenvolver e garantir o acesso à população sobre as questões de saúde que lhes forem pertinentes.

A Lei Orgânica da Saúde no 8080/1990, que cria o Sistema Único de Saúde, retoma esta afirmação constante na Constituição Federal Brasileira, reafirmando que a saúde é um direito fundamental do ser humano e dever do Estado prover as circunstâncias fundamentais ao seu pleno exercício, devendo ainda o Estado garantir a saúde mediante o estabelecimento de condições que assegurem o acesso, mas, deixa claro que o dever do Estado não exime a responsabilidade das pessoas, da família, das empresas e da sociedade nos assuntos relacionados à saúde. (BRASIL, 1990).

Em ambiente hospitalar, os medicamentos ficam armazenados comumente na farmácia e a dispensação é realizada por profissionais atuantes no setor, sendo o farmacêutico o membro da equipe responsável por todas as atividades desenvolvidas no âmbito da farmácia hospitalar. A rotulagem visualmente distinta de outros produtos permite a correta identificação do medicamento no ato da dispensação e evita erros de administração de medicamentos pelos profissionais de saúde.

Em farmácias e drogarias, os medicamentos podem ser adquiridos pelo próprio usuário ou outra pessoa solicitada por este, podendo ser comprados medicamentos disponibilizados no autosserviço e conhecidos como MIPs (Medicamentos Isentos de Prescrição), medicamentos que necessitam ser prescritos por um profissional de saúde habilitado para esta finalidade, incluindo-se ainda os medicamentos controlados, cuja prescrição ficará retida no estabelecimento dispensador do produto.

No caso de reações adversas ocasionadas por pacientes portadores de intolerância a lactose, por exemplo, o direito ao acesso às informações de saúde se torna essencial. Considerando que muitos medicamentos contém a lactose como excipiente, inclusive medicamentos controlados, caso o usuário venha desenvolver reação adversa ao medicamento por conter lactose, este produto provavelmente será inutilizado e o paciente precisará solicitar ao prescritor outra receita para efetuar uma nova compra. 
Casos assim poderiam ser evitados com frases de advertência nas embalagens, visto que a informação a respeito dos excipientes está inserida somente em bulário.

Medicamentos são disponibilizados em ambientes distintos, mas são utilizados com a mesma finalidade de prevenir, curar, aliviar os sintomas ou auxiliar no diagnóstico de doenças. Entendendo essas premissas, podemos perceber que as informações a respeito desses produtos devem chegar de modo eficiente aos usuários, para proporcionar o uso seguro e sem riscos adicionais, além daqueles conhecidos e já manifestados em bula.

As informações a respeito de produtos, especialmente aqueles relacionados à saúde, devem ser adequadas e claras a fim de apresentar de forma precisa todas as evidências que garantam a segurança quanto ao uso, conforme previsto no artigo $6^{\circ}$ do Código de Defesa do Consumidor (BRASIL, 1990).

A regulamentação sanitária é o caminho para se estabelecer e garantir esse direito ao consumidor de produtos farmacêuticos. Ainda, o setor industrial farmacêutico teria muito a ganhar com a disponibilização de informações mais eficientes na rotulagem, além daqueles exigidas pela legislação atual, visto que, produtos que agregam valor à segurança do consumidor e a segurança na prescrição por parte dos profissionais de saúde prescritores de medicamentos, teriam maior possibilidade de prescrição e venda.

O desenvolvimento industrial de material de embalagem e o direito às informações de saúde deveriam estar interligados. Considerando que profissionais da saúde por muitas vezes exercem longas jornadas de trabalho por dia, embalagens semelhantes representam um risco para a administração errônea e não colaboram para atender os critérios de segurança no uso de medicamentos.

Mudanças na rotulagem e embalagem de medicamentos poderiam minimizar a ocorrência de erros de medicação, alertar pessoas portadoras de problemas relacionados à lactose sobre reações adversas e propiciar o uso racional de medicamentos, garantindo o direto à saúde e as informações de saúde. 


\section{CONSIDERAÇÕES FINAIS}

Analisadas as normas sanitárias sobre rotulagem e embalagem de produtos farmacêuticos, foi possível encontrar conceitos e recomendações genéricas para o desenvolvimento da rotulagem e observou-se a falta de regras específicas para inibir que se ocorra possíveis erros de medicação derivados de rótulos e embalagens semelhantes.

Concomitantemente, não foi encontrada em nenhuma norma sanitária a determinação por parte da agência regulatória brasileira sobre a obrigatoriedade para as indústrias farmacêuticas inserirem a informação: 'CONTÉM LACTOSE', nas embalagens e rótulos de medicamentos, especificando aos profissionais de saúde e pacientes sobre a composição da fórmula farmacêutica diretamente nas embalagens secundárias: "parte externa da caixa".

Os custos advindos para os sistemas de saúde em todo o mundo gerados por erros de medicação e reações adversas são altos, e as consequências da semelhança e falta de informação sobre excipientes em rótulos e embalagens contribuem para o aumento dos gastos dispendidos e elevam a possibilidade de risco à saúde de todos.

Erros de medicação e eventos adversos derivados da rotulagem e embalagem de produtos farmacêuticos precisam ser investigados pelas autoridades em saúde pública e pela ANVISA, órgão vinculado ao Ministério da Saúde, a fim de buscar soluções para a questão evidenciada nesta pesquisa, e tentar encontrar meios que favoreça o uso racional de medicamentos alinhados com o desenvolvimento pelas indústrias farmacêuticas de rótulos e embalagens mais informativos do que somente comerciais.

A ocorrência desta situação aparentemente não tem comovido as indústrias farmacêuticas para o desenvolvimento de projetos de modo a criar novas soluções, proporcionando à padronização de embalagens e rótulos de medicamentos, esquecendo que os parâmetros de qualidade para atendimento as Boas Práticas de Fabricação devem ser observados desde os estudos de desenvolvimento e produção 
das formas farmacêuticas até o controle de qualidade e segurança no uso póscomercialização.

Simples ações da indústria de medicamentos poderiam melhorar a vida de pacientes e profissionais de saúde no manejo de medicamentos. A utilização de cores diferentes para diferenciar a rotulagem de fármacos, principalmente aqueles com potencial de interação medicamentosa moderada a grave, e a inserção de frase de alerta específica para produtos com lactose diretamente na parte externa em embalagens de medicamentos, poderiam evitar erros e facilitar o acesso às informações relevantes.

Essa pesquisa espera contribuir para que novos estudos sejam desenvolvidos, e providências sejam tomadas a respeito do tema, tanto pelas instituições públicas como pelo setor industrial farmacêutico, de modo a proporcionar que debates ocorram e soluções possam ser encontradas.

Cabe, primeiramente, a Agência Nacional de Vigilância Sanitária, como entidade responsável por desenvolver a promoção da saúde, o papel de reanalisar a legislação atual sobre rotulagem e embalagem de medicamentos e publicar novos atos normativos que solucionem as questões apresentadas nesta pesquisa.

Rótulos e embalagens vêm sendo a causa de erros de medicação e reações adversas relacionadas. A regulamentação sanitária é a maneira de proporcionar a prevenção e minimização de problemas relacionados aos medicamentos.

\section{REFERÊNCIAS}

ANACLETO, Tânia Azevedo et al. Erros de medicação e sistemas de dispensação de medicamentos em farmácia hospitalar. Clinics. São Paulo, v. 60, n. 4, p. 325332 , ago. 2005

Disponível

em:

<http://www.scielo.br/scielo.php?script=sci_arttext\&pid=S1807-

$59322005000400011 \& \mathrm{ng}=\mathrm{pt \& n}$ rm=iso $>$. Acesso em: 29 nov. 2019. http://dx.doi.org/10.1590/S1807-59322005000400011. 
ANVISA, 2019. Registro de medicamentos cresce 100\%. Disponível em: $<$ http://portal.anvisa.gov.br/noticias//asset_publisher/FXrpx9qY7FbU/content/registro-de-medicamentos-cresce-100-em2019/219201?p_p_auth=fJVL8wqt\&inheritRedirect=false >. Acesso em: 06 jan. 2020.

ARAUJO, Ana Carolina; BORIN, Maria de Fátima. Influência de excipientes farmacêuticos em reações adversas a medicamentos. Brasília Med. 2012;49(4):267-278. Disponível em: <https://pdfs.semanticscholar.org/e5a3/9e36b11ae4dc9336d3bd033fe80cd45f2df1.p df>. Acesso em: 15 jan. 2020.

AULTON, Michael E. Aulton delineamento de formas farmacêuticas. Michael E. Aulton, Kevin M. G. Taylor; [tradução Francisco Sandro Menezes]. Versão digital - 4 ed. - Rio de Janeiro: Elsevier, 2016.

BRASIL, 1988. Constituição da República Federativa do Brasil. Disponível em: <http://www.planalto.gov.br/ccivil_03/constituicao/constituicao.htm>. Acesso em: 20 nov. 2019

BRASIL, 1990. Lei no 8.078, de 11 de setembro de 1990. Dispõe sobre o Código de Defesa do Consumidor. Disponível em: <http://www.planalto.gov.br/ccivil_03/leis//8078.htm>. Acesso em 17 dez. 2019.

BRASIL, 1999. Lei no 9.782, de 26 de janeiro de 1999. Disponível em: <http://bvsms.saude.gov.br/bvs/saudelegis/anvisa/2006/prt0354_11_08_2006.html>. Acesso em: 15 de jan. de 2020.

BRASIL, 2016. Manual de Identidade Visual de Medicamentos do Ministério da Saúde. Disponível em: < https://www.saude.gov.br/artigos/672-assuntos/assistenciafarmaceutica/42827-arquivos-do-manual-de-identidade-visual-de-medicamentos>. Acesso em: 22 jan 2020. 
BRASIL, 2003. Resolução RDC no 333, de 19 de novembro de 2003. Disponível em: <http://bvsms.saude.gov.br/bvs/saudelegis/anvisa/2003/rdc0333_19_11_2003.html>. Acesso em: 27 out. 2019.

BRASIL, 2019. Resolução RDC no 71, de 22 de dezembro de 2009. Disponível em: <http://bvsms.saude.gov.br/bvs/saudelegis/anvisa/2009/res0071_22_12_2009.html>. Acesso em: 23 nov. 2019.

BRASIL, 2015. Lei no 13.236, de 29 de dezembro de 2015. Disponível em: $<$ https://www2.camara.leg.br/legin/fed/lei/2015/lei-13236-29-dezembro-2015-782195publicacaooriginal-149108-pl.html>. Acesso em: 27 out. 2019.

BRASIL, 2019. Resolução RDC no 301, de 21 de agosto de 2019. Disponível em: $<$ http://www.in.gov.br/web/dou/-/resolucao-rdc-n-301-de-21-de-agosto-de-2019211914064>. Acesso em 14 dez. 2020.

COSTA, Ana Luiza Fontes de Azevedo et al. Quando a cor ajuda. Einstein (São Paulo), São Paulo, v. 17, n. 1, eAO4410, 2019. Disponível em $<$ http://www.scielo.br/scielo.php?script=sci_arttext\&pid=S167945082019000100200\&Ing=en\&nrm=iso>. Acesso em 29 nov. 2019. Epub Dez 17, 2018. http://dx.doi.org/10.31744/einstein_journal/2019ao4410.

DE CASTRO, Ana Luiza Ferreira Meinen; AHLERT, Elias Ricardo; COLET, Christiane de Fátima. Avaliação do risco de reações adversas causadas por excipientes em formulações de anticoncepcionais. Revista Contexto \& Saúde, v. 10, n. 19, p. 146149, 14 jun. $2013 . \quad$ Disponível em: $<$ https://www.revistas.unijui.edu.br/index.php/contextoesaude/article/view/1496>. Acesso em: 15 nov. 2019.

GERMANA, Stefani P. et al. Presença de corantes e lactose em medicamentos: avaliação e 181 produtos. Rev. bras. alergia imunopatol; v. 32, v.1, p. 18-26, jan.fev. 2009. Disponível em: < http://www.sbai.org.br/revistas/Vol321/ART\%201-09\%20\%20Presen\%C3\%A7a\%20de\%20corantes\%20e\%20lactose.pdf>. Acesso em: 15 jan. 2020. 
ISMP, 2018. Estratégias de segurança do paciente no Brasil - O que já foi feito e o que ainda está por vir?. Disponível em: <https://www.ismp-brasil.org/site/wpcontent/uploads/2019/05/A----es-da-Anvisa-com-foco-seguran--a.pdf>. Acesso em: 22 jan. 2020.

LOPES, Diana Maria de Almeida et al. Análise da rotulagem de medicamentos semelhantes: potenciais erros de medicação. Rev. Assoc. Med. Bras., São Paulo, v. 58, n. 1, p. 95-103, fev. 2012. Disponível em $<$ http://www.scielo.br/scielo.php?script=sci_arttext\&pid=S010442302012000100021\&Ing=en\&nrm=iso>. Acesso em: 29 nov. 2019. http://dx.doi.org/10.1590/S0104-42302012000100021.

National Coordinating Council for Medication Error Reporting and Prevention. What is a medication error? Nova York: National Coordinating Council for Medication Error Reporting and Prevention; 2015. Disponível em <http://www.nccmerp.org/aboutmedication-errors>. Acesso em 20 de jan. 2020.

PEREIRA, Leandra Gonçalves; FERREIRA, Michelle Silva; MARQUES, Fabíola Pedrosa Peixoto, 2019. Intolerância à lactose e os aspectos legais da rotulagem. Disponível em: $<$ http://anais.unievangelica.edu.br/index.php/latosensu/article/view/4526>. Acesso em 15 jan. 2020

PESSANHA, Ana Flávia de Vasconcelos et al. Influência dos excipientes multifuncionais no desempenho dos fármacos em formas farmacêuticas. Rev. Bras. Farm. 93(2): 136-145, 2012. Disponível em: <http://www.rbfarma.org.br/files/rbf2012-93-2-2.pdf>. Acesso em: 15 jan. 2020

SENA, Cristina Santana et al. Excipientes farmacêuticos e seus riscos à saúde: uma revisão da literatura. Rev. Bras. Farm. 93(2): 136-145, 2014. Disponível em: <http://www.sbrafh.org.br/v1/public/artigos/2014050405000621BR.pdf>. Acesso em: 15 jan. 2020 
SILVA, Antonio Vinicios Alves da et al. Presença de excipientes com potencial para indução de reações adversas em medicamentos comercializados no Brasil. Rev. Bras. Cienc. Farm., São Paulo, v. 44, n. 3, p. 397-405, set. 2008. Available from $<\mathrm{http}$ ://www.scielo.br/scielo.php?script=sci_arttext\&pid=S151693322008000300009\&Ing=en\&nrm=iso >. Acesso em: 29 nov. 2019

WHO, 1998. Portal de informações sobre medicamentos essenciais e produtos de saúde. Relatório do 4 Grupo Consultivo da OMS sobre o papel do farmacêutico. Disponível em: <https://apps.who.int/medicinedocs/en/d/Jwhozip32e/>. Acesso em: 15 jan. 2020.

WHO, 2017. O terceiro desafio global da segurança do paciente da OMS: medicação sem danos. Disponível em: $<$ https://www.who.int/patientsafety/medication-safety/campaign/en/>. Acesso em 06 jan. 2020.

Enviado: Março, 2020.

Aprovado: Junho, 2020. 